\title{
$\widehat{A}$ Madridge
}

madridge Journal of Women's Health and Emancipation

Interconnecting Scientific World

Review Article

Open Access

\section{From Dawn to Dusk/Current Ethical Challenges Providers Face in Meeting Women's Needs at different Times in their Lives}

\author{
Edmund G Howe III ${ }^{\star}$ \\ Professor of Psychiatry, Professor of Medicine at USUHS and a Senior Scientist at the CSTS, USA
}

\section{Article Info}

*Corresponding author:
Edmund G Howe III*
Professor of Psychiatry
Professor of Medicine at Uniformed
Services University of the Health Sciences
Senior Scientist at Center for the Study of
Traumatic Stress (CSTS)
Bethesda, Md., USA
Tel: 3012953097
E-mail: Edmund.howe@usuhs.edu

Received: August 30, 2017

Accepted: September 18, 2017

Published: September 22, 2017

Citation: Howe III EG. From Dawn to Dusk/ Current Ethical Challenges Providers Face in Meeting Women's Needs at different Times in their Lives. Madridge J Womens Health Emancipation. 2017; 1(1): 29-35.

doi: $10.18689 / \mathrm{mjwh}-1000107$

\section{Copyright: @ 2017 The Author(s). This work is licensed under a Creative Commons Attribution 4.0 International License, which permits unrestricted use, distribution, and reproduction in any medium, provided the original work is properly cited.}

Published by Madridge Publishers

\begin{abstract}
Women have different medical needs from men that should be identified and met. In this piece I provide paradigmatic examples of such needs that women may have at three different times in their lives: when they are giving birth, at mid-life, and at the end of life. Specific examples used are mothers wanting to carry to term a fetus that has a lethal disorder, women who have been raped or sexually assaulted being fully treated and not "falling through the cracks", transgender women getting the medical assistance they may need to have their desired quality of life, and women who may have dementia or are caregivers having their autonomy and support needs maximally respected and met. These paradigms are intended to exemplify numerous similar needs that must likewise first be identified and then specially addressed.
\end{abstract}

Abbreviation: ART: Accelerated Resolution Therapy; PVS: Persistent Vegetative State.

Keywords: Ethical; Women's medical needs; Pregnancy; Rape; Sexual assault; Transgender; Dementia.

\section{Introduction}

Women have different medical needs from men that should be identified and met. This has not always been the case. An example is research. Much clinical research has been done more on men, for example, than on women [1]. In this piece I shall identify needs that women may have at three different times in their lives: when they are giving birth, at mid-life, and at the end of life. Each of these examples, both as a whole and individually, will be intended as paradigmatic of the kind of needs women also have in other areas that should similarly be identified and then specially addressed.

This piece is an ethical discourse and, thus, it is not based on empirical data. As with many ethical contributions to the literature, most of the issues discussed here were suggested by patients who described what they felt was for them a bad or unfair medical outcome. They reported their pain in a range of different forums. Some spoke, for example, in a public meeting, as at the annual meeting of the American Society of Bioethics and Humanities (ASBH); others revealed the harm they felt to ethics consultants, an ethics committee or to me in the course of a psychotherapy session.

The approach I have used here to assess the ethical issues brought to my attention is primarily the traditional approach to analyzing ethical problems: namely, the use of moral reasoning or rational argumentation. One first looks at the morally relevant facts, including those that may occur in the future, then considers the predominant values, 
deontological and consequential, that bear on the ethical issues and conflicts, next, evaluates the ethical pros and cons on each side, and finally seeks the best ethical argument and answer, based on the abstract ethical principles and values that should prevail.

The remaining question warranting comment is how these particular issues prioritized here were chosen. There were two criteria. The first was what issues seemed to be most important to these patients, based on what they have said and the significance they placed on them. The second was which issues involved changes that providers could, perhaps, implement now. The hope, then, is that in response to this discussion, patients, their loved ones, and providers can see new changes that providers can immediately bring about. Having seen these and their rationales, it may be providers will at least consider them and, if they do, the women encountering the ethical conflicts addressed here may benefit.

\section{Issues Associated with Pregnancy}

Mothers - and fathers - may deeply love their children when they cannot as deeply love back and when they know that these children will soon die. An example here, surpassing perhaps any, is a mother who had a child who had anencephaly. This infant came to be known publically as "baby K" [2]. These children, as far as we know, can't think or feel. This was thought, however, to be true also of adult patients in what was known as a persistent vegetative state (PVS) until recent years. Now we know that substantial numbers of these patients have or will develop intact areas or islands within their brains that give them awareness [3]. We may never be able to know whether infants with anencephaly have somewhat comparable islands of awareness, but even without this awareness, the mother of baby $\mathrm{K}$ loved her child greatly nonetheless.

She accordingly wanted baby K's providers to keep her child alive, though these infants usually die within no more than two weeks or so. This may be because, in some cases, providers give these babies less than full treatment. Their primary goal is not usually to keep these infants alive. The hospital staff opposed keeping baby $\mathrm{K}$ alive. Her mother went to court to try to compel this staff legally to do all they could to sustain her daughter's life. She succeeded. The judge ruled in her favor and indicated that if a staff wanted to override a parent's request to maintain his or her child's life, this probably should be carried out only if this was decided by legislators elected by the people, as opposed to by a judge in a court. Baby $\mathrm{K}$ lived on, then, for approximately two and one-half years.

A recent case in Britain suggests that we in the U.S., as a society, could go a different way. A court decided there that doctors must stop their life-preserving treatment of Charles Gard, an eleven-month-old infant, even though some thought it possible that experimental treatment might still be beneficial for him [4]. Taken together, regardless of these disparate outcomes, these cases pose a question critical to these children, these mothers, and both these children's parents: When should providers respect parents' requests to keep their children alive?

An example most paradigmatic of how this question may arise today and, more importantly, how immediately providers could resolve it is the following: What should providers do when mothers know that the fetus they are carrying has a lethal illness and they want to carry this fetus to term so that they can have at least some moments with this child? They may know that they will have only hours, days, or months with their child before he or she will die. Still, they may rightly imagine that the time they will have with their child to them will be precious, both at this time and ever afterwards. In the past, when providers have discerned and then informed pregnant women that their newborn infant will die soon after birth, these providers often have discouraged these mothers from carrying these children to term. Some mothers, in response, aborted these fetuses. Others did not.

Mothers in both these groups sometimes, afterwards, however, much resented these providers for not having supported them in their wishes to carry these fetuses to term so that they could then hold them alive as long as they could. Some mothers who did carry them to term found these moments, they reported later, among those most meaningful to them in their lives. Consequently, some of these women later have formed groups to help other women who are experiencing this conflict or may encounter it. These groups help women who are pregnant and want to carry their children to term to be able to do this and then to be able to hold these children and be with them as long as possible after they are born [5].

A closely related, ethically more complex but much less common problem may arise when mothers and parents know that their fetus has such a lethal illness and they then want their child delivered by a caesarean section so that he or she will be less likely to die than the child would be if they underwent a vaginal birth. Here, there are greater risks to the mother from a caesarean delivery, but the values of respecting the mother's wishes and giving the child a possibly better outcome may, to these mothers, at least, warrant this.

"Deborah", for example, presented to labor and delivery at thirty seven weeks' gestation after her fetus had been diagnosed with trisomy 13 . One-half of these children die as a result of a miscarriage or are stillborn, the median life expectancy of these infants if they are born alive is seven to ten days, and only 5 to 10 percent of these children born alive live beyond one year. Deborah hoped to be able to hold her baby and have him baptized if he was alive at birth. She also hoped her child would have as painless a death as possible and that a caesarean section would best achieve this. Yet, she had had three prior vaginal deliveries with labor progressing normally, and since her fetus's poor prognosis was unlikely to improve with caesarean delivery, there was no maternal or fetal indication for a caesarean section. The ethical question posed, therefore, was whether her doctors should do what she wanted solely to respect her autonomy [6]. 
The challenge here for the future is for providers to find ways such as this to more and most respect mothers' similar needs and desires. Areas in which this challenge exists are many. As the above example suggests, providers may, in some contexts, still have a way to go. Some mothers and parents who have anencephalic babies want, on the other hand, unlike baby K's mother, to give meaning to their children's lives by having providers transplant these infants' organs to others so that these organs can then benefit others so that hopefully they can continue to live [7]. In this case, it might be ethically optimal for providers to fulfill these parents' request if they can. Other examples are less closely related to the cases above. There are, for example, a plethora of ethical questions involving mothers who want to deliver with the help of midwives at home as opposed to in hospitals when they could go to hospitals. Neonatologists, pediatricians, and obstetricians may oppose this because they have special equipment in the hospital. They may use this equipment to treat these mothers' infants if they are born in distress $[8,9]$.

The ethical challenges these and other situations involving childbirth pose also involve resources. In the case of women wanting to give birth to their infants though they know they will die, for example, this foreseeably may require more of society's resources. How these costs should be weighed and who should decide how much if any moral weight these costs should have are, then, additional questions that must be considered. The balancing of these competing interests and their optimal resolutions may in many cases need to be reconsidered and renegotiated if mothers' interests are to be furthered to the degree that they can and should be. It may be possible, practically, to progress only asymptotically to these goals but this effort is ethically warranted now nonetheless.

\section{Midlife Issues}

There are numerous special issues particularly women may encounter in their adolescent or adult life. An example, terrible but common, is their vulnerability to being raped. An entirely different kind of vulnerability now becoming more publically discussed is the vulnerability of transgender women. This section will consider these two examples as paradigms for other kinds of challenges that can occur also at mid-life and to which providers should additionally attend.

\section{Rape}

Rape and other kinds of sexual assault affect especially women. The special problems these women may face again are many [10]. Providers here have many initiatives and interventions they could carry out that may be beneficial. One involves, for example, their seeking to further ways in which society might more prevent these wrongs from occurring [11]. In this piece, though, I shall focus on efforts providers can pursue with individual patients who have been raped or sexually assaulted.

The particular group I shall focus on, as particularly representative of women whose needs may go less noticed, is women who have been raped under circumstances such that they may not be believed by others. These circumstances may be those, for example, in which the facts are such that they cannot even bring their case before a court. This may be because the evidence that rape as opposed to consensual sex occurred is legally insufficient to reach the required thresholds to bring the case to court. An added harm that these circumstances may bring about for these women is that others to whom they want to share what has happened to them may not believe them. Then they may be isolated in bearing their pain and the effects of this trauma.

One woman was raped, for example, when she stayed after hours doing work with a colleague. There were no witnesses and she did not have vaginal bruises or injuries. She reported immediately afterwards what had happened both to the police and her work but both informed her that under these circumstances there was nothing she could do. Her emotional pain at not being able to take any action was exacerbated by her still having to encounter this colleague regularly in her work if she wanted to keep this job which she did. Adding to her angst also was her thought that she would not be able to protect other women from the colleague who had raped her in the future. She became significantly depressed. Fortunately, with medication and psychotherapy, in time she did well.

Providers, as others, may add to these women's pain also by misinterpreting different aspects of their behavior. A representative if rare example is women who continue after being raped or assaulted to engage in dangerous behavior, as to go to the same neighborhood in which the rape or assault occurred [12].

Providers may wrongly infer and then share with these patients that they believe that these patients sought and are still seeking to be so abused. This inference is logically plausible, but may be the opposite of the truth. This behavior may be due, for example, to these patients, for reasons outside their awareness, seeking to restore and thus be able to retain their previous world view that it is possible to live safely in this life. They may re-expose themselves to the same dangerous circumstances in an unconscious attempt, albeit futile, to prove to themselves that the rape or assault that occurred was, in regard to their world view, misleading because it was wholly anomalous. They may hope that by going to this same place and not being harmed that they can restore for themselves the assumption that they and the environment they live in is as they had seen it, namely, as safe. Providers, of course, should, nonetheless, try to help these patients recognize the real dangers their enacting these "repetition compulsions" brings about and help them understand that this behavior will not enable them to overcome their newly acquired fears nor allow them to restore and retain their prior view that the world is as safe as they would wish that it is.

Providers must also avoid making what is, perhaps, the most toxic of all conclusions, namely, that in some way or other, these women contributed to their being raped by their own behavior. The assumptions they would be making if they 
believe this are erroneous. Yet, even if they just imagine this and allow this belief within them to persist, in some way or other, possibly even non-verbally, they may convey that they believe these women brought this on themselves. This may be devastatingly demeaning. Assuming then that providers can avoid responses that would harm these women further, they must in addition be careful also not to coerce these women further in any way. They should not, for example, even inadvertently, place pressure on these women to share the details of the rape when they don't want to. The cardinal rule here is rather for providers to most-of-all and first help these women feel safe.

It is generally important that providers not even imply to these women a "should", as that they should recite what happened. Providers may evoke in patients shame by telling them what they should do, especially when patients feel, perhaps rightly, that this would be harmful to them. The provider may be convinced of the likely benefits of what he or she recommends, but this does not mean that the patient will necessarily respond in this same way. Patients may feel worse about themselves, however, regardless, for not being able to do what their provider tells them they should do. Rather, sharing, if this will occur, may take time. Again, the last thing providers should do with these patients is to press them for details. If they do, these patients also may feel too much pain to even come back.

There are effective, evidence-based treatments these women should know are available to help them overcome the effects of this trauma. Providers should know this and encourage this. There are standard and well-proven therapies now available. There is now also a new treatment for overcoming past trauma, including rape and assault, that may not even require patients to tell their psychotherapists details about their trauma. This therapy is called Accelerated Resolution Therapy or ART. This therapy involves patients making eye movements that are guided by their therapists, and using their imagination, patients can change negative to positive images and respond very much better after this when they have memories of the trauma which has occurred $[13,14,15]$.

This therapy though not yet anywhere near as well studied as the standard approaches may help patients who experienced trauma even in the distant past and it may take very few sessions to succeed. One woman had been repeatedly raped throughout her early adolescence by a much older brother and she had told no one because he had threatened her with bodily harm if she did. She changed her memory of the horrors she experienced each time this happened to this brother while raping her disintegrating into the soil and then fertilizing it so that it grew beautiful flowers which she then gave away in abundance to children that received them with glee. As this example particularly suggests, there is no place here then for providers to be therapeutically nihilistic.

The challenge here, rather, is for providers to help these women recover so that they do not go on with their lives more limited than they need be due to what they have experienced. Put simply, providers must seek to insure that these women, deeply injured, don't fall, in a short time or later, "through the cracks". This is an outcome, unfortunately all too likely since these women may feel too damaged, too hopeless, and/or too helpless as a result of having been raped to take the steps necessary to subsequently most help themselves [16].

A final, specific challenge some of these women may confront is whether they should try to forgive the person who has assaulted them. These women may feel that this is just the opposite of what they would ever do. Some may, on the other hand, find their forgiving very beneficial [17]. This decision whether or not to forgive may be particularly difficult if the person sexually offending is their doctor or therapist [18]. Here these patients' knowledge that they may ruin their providers' career and their often having previously had a good relationship with them may make their reporting or forgiving this provider an extremely difficult decision. These patients' new, subsequent providers may find themselves wanting to report these offenders, but ethically, preferably, they should probably in most or all cases leave this decision up to their patients [19]. If they do not, they risk violating these patients' trust, and ethically this may be a greater ethical wrong and cognitive error than even their helping to stop such providers from harming other future patients.

A patient had seen her therapist for some time when he for the first time made sexual advances to her. She felt anxious and confused, and remained passive initially, allowing him to proceed. He then, apparently caught himself and stopped. He later, after the session called her at home expressing his regret and begged her forgiveness. She was haunted thereafter with guilt that in not more resisting she had been complicit in allowing this and she struggled and painfully obsessed over whether she should report him. She wanted to protect other patients but thought he had most likely learned his lesson and she didn't want to ruin his career. She too in time fortunately did well with the help of medications and therapy.

\section{Needs of Transgender Women}

Rape is an example of a harm women suffer much more than men. Transgender persons, in contrast, whether male or female, both now, in this society are vulnerable to great harms $[20,21]$. Providers need then to help all transgender persons meet their needs, though in this piece, I shall only discuss their meeting the needs of these women.

A first problem that particularly psychotherapists should address is the risks that may come about if they are asked to serve in two roles, one as therapist, the other, as assessor [22]. That is, they may initially be seeing these patients for therapy, but later on be asked to offer their recommendation as to whether another provider should give them hormones or irreversible surgery. Therapists would face, then, this conflict: if they recommend anything other than what the patient would want, their patients may see them as betraying them. Their therapeutic alliance may be lost. Patients anticipating this bind may during therapy say what they say not because this is what they feel, but because they believe that this is what 
their therapist must hear to recommend for them later what they want .Therapists optimally, may then best manage this risk by discussing it with these patients before this conflict occurs. Together they may then agree that the therapist will not make later recommendations. This solution may be suboptimal, however, because these patients' therapists may know these patients far better than anyone else and thus may be the only providers who can make the most insightful recommendations for these patients.

A second way in which providers may particularly help these patients is to advocate for them to be able to have the interventions they need and want and to have these at costs they can afford. This may mean, for instance, that providers help them make the case for their requests to their medical insurance companies. Providers may here indicate, for example, that, to them, an intervention is essential to their well-being as opposed to its only being desirable [23]. An example here for these women is breast augmentation [24]. This surgery may be necessary for them to perceive accurately that they are not attracting undue attention from others due to their appearance. They may continue to attract the attention of others for this same reason even though their appearance has changed somewhat after they have begun taking female hormones. The obverse concern may occur also for transgender men. They may take male hormones but still need surgery to alter their chest contour. Again, this may be necessary to enable them to avoid attracting unwanted attention as when they are merely walking down a street.

Providers should know that in general there are two things that transgender persons most likely most want for themselves. The first is to be able to be authentic and to live as the gender they are. The second is to be able to engage with other people as others can. Taken together, these two needs mean that they want to be able to engage with others in a way that others respond to them based on who they are, as opposed to their responding first and perhaps always most on the basis of how they appear. These persons' being able to have breast augmentation or contouring surgery may be necessary to bring both these ends about.

Providers accordingly should also not underestimate the extent to which these person's quality of life may be affected and impaired until they can become and live as the gender that they are. One woman when younger and living as a boy had, for example, his parents reported, been miserable throughout her early life. It was only when she could express how she felt and underwent the physical changes to appear as a woman that her mood lightened and after this persisted. Her parents said they were astonished because this was the first time in her whole life they had seen her happy.

A final and particularly pronounced area in which these women may need their providers' help and support is in regard to the needs and wants they have in regard to being able to have and raise children [25]. These women may need, for example, female hormones, but these hormones may adversely affect their sperm over time. Thus, the best solution for this may be for them to be able to freeze and save their sperm so that then they can later use this sperm to have children biologically related to them if this need arises and this is then what they want [26]. Again, this kind of intervention, freezing eggs, may likewise be optimal for transgender men. They may want to save their ova if they will be taking male hormones.

Another concern that can arise for these women is in regard to their being able to have and enjoy having a family. They may need providers' help to not only be able to conceive a child with the help of medical interventions but need help also in merely being able to adopt a child. Providers and ethics committees have and may be reluctant to approve adoption measures on the ground that transgender persons as parents and couples may be less adequate as parents for their children.

One transgender woman had been, for example, previously, for some time, significantly depressed. This was in part it appears because she had had then for a long time unremitting pain. She then got relief from this pain and her depression remitted. She then sought with her partner to adopt a child but to do this she needed an approval recommending this from her physician. Her doctor was reluctant to give this approval because she might again become depressed. It is more than plausible, however, that the true ground underlying this provider's reluctance was that this woman would be a transgender parent. This physician after discussion gave this approval.

Providers for these patients should know then that this claim that transgender parents are less adequate parents is spurious [27, 28]. There is no evidence for this concern. These parents may even be better parents on the average than others. This is because these persons will have experienced greater suffering than most other parents. They may, as a result of this, be able to empathize more with their children when they suffer and thus be more compassionate. Providers, consequently, should treat these women when they come for help with fertility or to adopt like they treat all others making these requests. Providers should not even refer these women's requests to ethics committees because this, too, is unjustifiably discriminatory.

\section{Dementia at the End of Life}

A disorder that particularly occurs at the end of life and again may affect both women and men is dementia [29, 30]. This also may become increasingly more common in the years to come. This outcome may be terrifying for people to both anticipate and experience [31]. These patients may come in time to not know, for example, partners to whom they have been married for decades.

One couple had been married, for example, for over fifty years when a woman's husband developed dementia and then rapidly declined. He had to be placed in a nursing home and over just a few years lost the capacity to recognize by name both her, his long-time wife, and me. She found this sad but had tried to prepare herself for this. She most poignantly found, however, that even though he no longer seemed to know who she was, he would respond when she went to kiss him by kissing her back as if on some non-verbal level he remembered her. 
Commonly, providers' sole priority when seeing older patients who tell them that they have noticed a decrease in memory is to "work up these patients" for dementia. They believe they must make this diagnosis if they can. Further, now there are means by which they can predict to a greater extent that people will have dementia before this occurs. The need to diagnose dementia that will be or is at least extremely likely to occur later is also increased now by the need to do this early on in people's lives for purposes of research [32]. It is now believed that most likely for a treatment to later be successful, it will have to be given early on in life, as when patients are in their twenties. Research participants must be determined at this time to be at higher risk for it to be possible to conclude that a new treatment is effective.

Providers and researchers may, however, prior to doing this testing, want in some cases to maximally respect these patients and maximally benefit them by telling them about the pros and cons of their accepting this early testing prior to their carrying it out. They may tell them, for instance, that what memory loss they have may be merely that which goes with aging and that if their memory loss does not interfere with their life, they may want to hold off for a bit before they undergo definitive testing. The gain from waiting is that if they are diagnosed earlier than they "need to be", this knowledge may, once they know, place a dark curtain over their remaining lives.

Patients so informed may decline further testing. One patient with some minor complaints of decreased memory consistent with normal aging was for example informed of the likely pros and cons of being tested before this testing was begun. She became adamant: "I can speak and still speak four languages," she somewhat shrieked. While it is still possible that she had early dementia, she clearly didn't want this testing at this time. This question whether to risk imparting possibly frightening personal information has arisen concomitantly in regard to incidental findings in research settings. This particularly is the case, for example, in regard to recent research testing for genes. This testing may show for example that research participants are at high risk for a future cancer. This knowledge too may then place a dark cloud over their remaining life.

Providers, additionally, should ask these patients before they do this testing whether they have long term health care insurance in case they later develop dementia. If they do not, they may want to get this insurance prior to their being tested, because otherwise this may affect whether they can get this insurance or how much it will cost if they do.

Providers should also urge caregivers caring for persons with dementia too to find support groups and help them in this endeavor, as by giving them the contact information they will need to be able to find these supportive others [33]. This is particularly important for women because they take on care giving roles more often than men. These support groups may make the difference between these people's lives becoming empty as they feel and become more and more isolated and overwhelmed versus, on the other hand, becoming able to find ways with the help of others in support groups to still be able to create and live lives having zest [34]. There may be few interventions for caregivers more important for providers to offer than contacts with these support groups. If caregivers do better, this benefit may also, of course, then benefit also those they care for.

A final case example illustrating an additional concern here likely to be hidden involves how relatives decide to divvy up the needs to care for loved ones with dementia. One middle aged sibling, for example, chose to travel a considerable distance to relieve her brother from these responsibilities regularly. She felt though that since he had the lion's share of care taking responsibilities for their parent, she had no need to seek out support for herself. This may have in this instance been the case as it may be also in other cases but she added to this two thoughts that made this less plausible. First, she expressed her guilt for leaving more of their parent's care to her brother. Second, she said that since he did so much more, she didn't deserve to get support for herself. Providers, accordingly, should remain somewhat wary of all persons caring for loved ones with dementia who deny that they need more support than they have. This denial, especially if adamant, may in fact be an indication that they do need more support than they have.

\section{Conclusion}

Women may face exceptional difficulties in this and other societies. Consequently, providers should seek to identify those areas in which women may face greater problems and then take initiatives to address them [35]. This article raises several paradigmatic examples. Some of those discussed occur during childbirth, some at mid-life, and some at the end of life when women either have or care for loved ones with dementia. The discussion has stressed particularly the needs of women who want to give birth to children though they know that these children will shortly die, the needs of women who have been raped under circumstances such that they can't bring what happened before a court, the core needs of transgender women, and the needs of women who have memory problems as they age.

These few examples are intended to exemplify not only these but other, like needs that providers can first seek to detect and then take initiatives to try to better meet, such that they may bring about greater equality for women by pursuing these measures $[36,37]$. These and similar endeavors should, of course, analogously, also be simultaneously identified and then pursued for all groups who now are also more vulnerable within our society.

\section{Disclaimer}

The opinions or assertions contained herein are the private views of the author and are not necessarily those of the AFRRI, USUHS, or the Department of Defense. The funders had no role in study design, data collection, and analysis, decision to publish, or preparation of the manuscript. 


\section{Conflict of interest}

The author confirms that there is no conflict of interest regarding this manuscript.

\section{References}

1. Stefanice ML. Not just for men. Scientific American. 2017; 317(3): 52-57. doi: 10.1038/scientificamerican0917-52

2. Tousignant $M$, Miller $B$. Baby K's mother gives her the prayer that many deny she has. Washington Post. 1994; A1, A8-9.

3. Evers K. Neurotechnological assessment of consciousness disorders: five ethical imperatives. Dialogues in Clin Neurosci. 2016; 18(2): 155-162.

4. Wagner J, Bever L, Bernstein L, Trump offers to help ill British baby, The Washington Post. 2017, A3.

5. Lizotte, M-S. Optimizing empathy and compassion during end-of-life conversations with parents in neonatology: parents' and providers' perspectives. 2016 American Society of Bioethics and Humanities Meeting, Washington, D.C., 2016: 3:15-4:15.

6. Mayor MT. Case Study. "Lethal" Fetal Anomalies and Elective Cesarean. Commentary. Hastings Cent Rep. 2015; 45(6): 13-14.

7. Sarnaik AA. Neonatal and Pedialtric Organ Donation: Ethical Perspectives and Implications for Policy. Front Pediatr. 2015; 17(3): 100. doi: 10.3389/ fped.2015.00100

8. Grünebaum A, McCullough LB, Arabin B, Dudenhausen J, Orosz B, Chervenak FA. Underlying causes of neonatal deaths in term singleton pregnancies: home births versus hospital births in the United States. $J$ Perinat Med. 2017; 45(3): 349-357. doi: 10.1515/.jpm-2016-020

9. Sandall J, Soltani H, Gates S, Shennan A, Devane D. Midwife-led continuity models versus other models of care for childbearing women. The Cochrane Library. 2016; doi: 10.1002/14651858.CD004667.pub5

10. Khambati N. India's two finger test after rape violates women and should be eliminated from medical practice. BMJ. 2014; 348: g3336. doi: 10.1136/ bmj.g3336

11. DeGue S, Simon TR, Basile KC, Yee SL, Lang K, Spivak H. Moving Forward by Looking Back: Reflecting on a Decade of CDC's Work in Sexual Violence Prevention, 2000-2010. J Womens Health (Larchmt). 2012; 21(12): 12111218. doi: 10.1089/jwh.2012.3973

12. van der Kolk BA. The compulsion to repeat the trauma. Re-enactment, revictimization, and masochism. Psychiatr Clin North Am. 1989; 12(2): 389-411.

13. Kip KE, Rosenzweig L, Hernandez DF, et al. Randomized controlled trial of accelerated resolution therapy (ART) for symptoms of combat-related post-traumatic stress disorder (PTSD). Mil Med. 2013; 178(12): 1298-1309. doi: 10.7205/Mil Med-D-13-00298

14. Kip KE, Hernandez DF, Shuman A, et al. Comparison of Accelerated Resolution Therapy (ART) for Treatment of Symptoms of PTSD and Sexual Trauma Between Civilian and Military Adults. Mil Med. 2015; 180: 964-971. doi: 10.7205/Mil Med-D-14-00307

15. Waits W, Marumoto M, Weaver J. Accelerated Resolution Therapy (ART): a Review and Research to Date. Curr Psych Reps. 2017; 19(3): 18. doi:10.1007/s11920-017-0765-y

16. Nathanson DL. Understanding what is hidden. Shame in sexual abuse. Psychiatr Clin North Am. 1989; 12(2): 381-8.

17. Wade NG, Hoyt WT, Kidwell JE, Worthington, EL. Efficacy of psychotherapeutic interventions to promote forgiveness: a meta-analysis. J Consult Clin Psychol. 2014; 82(1): 154-170. doi: 10.1037/a0035268

18. DuBois JM, Walsh HA, Chibnall JT, et al. Sexual violation of patients by physicians: a mixed-methods, exploratory analysis of 101 cases. Sex Abuse. 2017; 1: 1079063217712217. doi: 10.1177/1079063217712217

19. Nass D. Confidentiality and the rape victim: ethical intent versus political reality. J Clin Ethics. 1991; 2(1): 66-71.
20. Zagorski N. Transgender students may think more about suicide than peers. Psychiatric News. 2017; 52(16): 17.

21. Fowler MD. Unladylike Commotion: Early feminism and nursing's role in gender/trans dialogue. Nurs Inq. 2017; 24(1). doi: 10.1111/nin.12179

22. Fraser $L$, Knudson $G$. Past and future challenges associated with standards of care for gender transitioning clients. Psychiatr Clin North Am. 2017; 40(1): 15-27. doi: 10.1016/j.psc.2016.10.012

23. Grossman AH, Park JY, Russell ST. Transgender youth and suicidal behaviors: applying the interpersonal psychological theory of suicide. J Gay Lesbian Ment Health. 2016; 20(4): 329-349. doi: 10.1080/19359705.2016.1207581

24. Wierckx K, Gooren L, T'Sjoen G. Clinical review: breast development in trans women receiving cross-sex hormones. J Sex Med. 2014; 11(5): 12401247. doi: $10.1111 / \mathrm{jsm} .12487$

25. Jin $\mathrm{H}$, Dasgupta $\mathrm{S}$. Disparities between online assisted reproduction patient education for same-sex and heterosexual couples. Hum Reprod. 2016; 31(10): 2280-2284. doi: 10.1093/humrep/dew182

26. Wierckx K, Stuyver I, Weyers $S$, et al. Sperm freezing in transsexual women. Arch Sex Behav. 2012; 41(5): 1069-1071. doi: 10.1007/s10508-012-0012-X

27. Farr RH, Patterson CJ. Coparenting among lesbian, gay, and heterosexual couples: associations with adopted children's outcomes. Child Dev. 2013; 84(4): 1226-1240. doi:10.1111/cder.12046

28. Farr RH. Does parental sexual orientation matter? A longitudinal followup of adoptive families with school-age children. Dev Psychol. 2016; 53(2): 252-264. doi: 10.1037/dev0000228

29. Hellström I, Eriksson H, Sandberg J. Chores and sense of self: gendered understandings of voices of older married women with dementia. Int J Older People Nurs. 2015; 10(2): 127-135. doi: 10.1111/opn.12062

30. Yarns BC, Abrams JM, Meeks TW, Sewell, DD. The mental health of older LGBT adults. Curr Psychiatry Rep. 2016; 18(6): 60. doi: 10.1007/ s11920-016-0697-y

31. Davis DS. Alzheimer disease and pre-emptive suicide. J Med Ethics. 2014; 40(8): 543-549. doi: 10.1136/medethics-2012-101022

32. Davis DS. Ethical issues in Alzheimer's disease research involving human subjects. J Med Ethics. 2017. doi: 10.1136/medethics-2016-103392

33. Barrett $C$, Crameri $P$, Lambourne $S$, Latham JR, Whyte $C$. Understanding the experiences and needs of lesbian, gay, bisexual and trans Australians living with dementia, and their partners. Australas J Ageing. 2015; 34 Suppl 2: 34-8. doi: 10.1111/ajag.12271

34. Singh AA. Moving from affirmation to liberation in psychological practice with transgender and gender nonconforming clients. Am Psychol. 2016; 71(8): 755-762. doi 10.1037/amp0000106

35. Dartnall $E$, Jewkes R. Sexual violence against women: the scope of the problem. Best Pract Res Clin Obstet Gynaecol. 2013; 27(1): 3-13. doi: 10.1016/j.bpobgyn.2012.08.002

36. Finlayson $C$, Johnson EK, Chen $D$, et al. Proceedings of the working group session on fertility preservation for individuals with gender and sex diversity. Transgend Health. 2016; 1(1): 99-107. doi: 10.1089/trgh.2016.0008.

37. Fredriksen-Goldsen LI, Jen S, Bryab AE, Goldsen J. Cognitive impairment, Alzheimer's disease, and other dementias in the lives of lesbian, gay, bisexual and transgender (LGBT) older adults and their caregivers. J Appl Gerontol. 2016; 1: 733464816672047. doi: 10.1177/0733464816672047 